\title{
ATHLI16: THE ATHENS LIDAR INTERCOMPARISON CAMPAIGN
}

\author{
Aldo Amodeo ${ }^{1^{*}}$, Giuseppe D'Amico ${ }^{1}$, Aldo Giunta ${ }^{1}$, Nikolaos Papagiannopoulos ${ }^{1}$, Alex Papayannis ${ }^{2}$, \\ Athina Argyrouli ${ }^{2}$, Maria Mylonaki ${ }^{2}$, Georgios Tsaknakis ${ }^{2}$, Panos Kokkalis ${ }^{2}$, Ourania Soupiona ${ }^{2}$, \\ Chris Tzanis ${ }^{3}$ \\ ${ }^{I}$ National Research Council - Institute of Methodologies for Environmental Analysis (CNR-IMAA), Italy, \\ *aldo.amodeo@imaa.cnr.it \\ ${ }^{2}$ National Technical University of Athens, Laser Remote Sensing Unit, Greece \\ ${ }^{3}$ National and Kapodistrian University of Athens, Department of Physics, Greece
}

\begin{abstract}
The results of the ATHLI16 (ATHens Lidar Intercomparison) campaign, held in Athens from $26 / 09$ to $07 / 102016$ are presented. The campaign was performed within the Lidar Calibration Centre activities (EU H2020 ACTRIS-2 project) to assess the performance of the EOLE lidar system (NTUA, Athens, Greece), operating within EARLINET, by comparing against the EARLINET reference lidar system MUSA (CNR-IMAA, Potenza, Italy). For both lidars only products retrieved by the EARLINET Single Calculus Chain have been compared.
\end{abstract}

\section{INTRODUCTION}

EARLINET, the European Aerosol Lidar Network [1], was established in 2000 with the aim to provide a statistical significant and high quality database of aerosol profiles at European scale. After the first phase, from 2000 to 2003, in which the network was established as a research project funded by EU, EARLINET was funded again by EU under the projects EARLINET-ASOS (Advanced Sustainable Observation System) and ACTRIS (Aerosol, Clouds, and Trace gases Research Infrastructure), and presently it is funded in the frame of the EU project ACTRIS-2 (EU H2020 project) [www.actris.eu]. The network has been growing continuously over the years and several new stations have joined. At present, it consists of 28 advanced lidar stations distributed over 17 European countries. Most of the network instruments have been developed individually and therefore they are not standard systems. In order to guarantee the quality of the data from all the lidar systems, a quality assurance (QA) strategy has been developed both at algorithm and instrument levels. In particular, at instrument level, a direct intercomparison has been planned for all the network lidars against reference systems. Such intercomparison is made every time a new station joins the network or when a station performs a substantial upgrade on an already intercompared system. The first intercomparison campaign was carried out in 2009 (EARLI09 - EARlinet Lidar Intercomparison campaign 2009), involving 11 colocated lidar systems from nine countries [2]. This campaign was particularly important because it allowed to fix the quality standards for the EARLINET systems and to define five reference lidar systems to be used in the future intercomparison campaigns. After that, further six campaigns have been carried out, involving further eleven lidar systems and more are planned in the near future.

In this paper, the ATHLI16 (ATHens Lidar Intercomparison 2016 measurement campaign) is presented. The campaign was held in Athens (Greece) from 26 September to 7 October 2016, within the services provided by the Lidar Calibration Centre (LiCal) [3]. LiCal is a multiinstallation facility located in Romania (INOE), Germany (LMU), and Italy (CNR-IMAA), established in the frame of the ACTRIS-2 project and offering a wide range of services to test and calibrate lidars and ceilometers, starting from the characterization and optimization of single components, to the assessment of the whole system's performance, and training of instrument operators. The ATHLI16 campaign allowed to check the performance of EOLE, the lidar system running in Athens EARLINET station, through the comparison with the EARLINET reference lidar system MUSA (MUltiwavelength lidar System for Aerosol measurements), operated by CNR-IMAA in Potenza, Italy. 


\section{METHODOLOGY}

The used methodology has been described in detail by Wandinger et al. [2]. The goals of these campaigns are the verification of the performance of the systems in different atmospheric conditions, the identification of the main system deficiencies (e.g. optical misalignment, detector saturation, experimental setup, electronic problems) leading to systematic errors in the aerosol products, and to figure out technical solutions to fix instrumental problems. As a first step, a set of tests are performed for each optical channel to check the optical alignment (Rayleigh-fit and telecover tests), the trigger delay, the dark current (to evidence electronic distortions), the detector saturation and several instrumental parameters [4]. As a second step, the range corrected signals (RCS) are compared in terms of relative differences in the PBL, in the layers and on the whole measurement range. The agreement of the signals is evaluated according to the EARLINET standards $[2,5]$.

The EOLE Raman lidar system is located at the National Technical University of Athens (NTUA) $\left(37.97^{\circ} \mathrm{N}, 23.79^{\circ} \mathrm{E}, 212 \mathrm{~m}\right.$ a.s.1.) [6]. The MUSA Raman lidar system [7] was located at an altitude of $200 \mathrm{~m}$ a.s.l. The difference in altitude between the locations of the two systems (12 m) was taken into account in the data analysis and comparison. Both EOLE and MUSA are able to measure aerosol backscatter coefficient at 1064, 532 and $355 \mathrm{~nm}$, and aerosol extinction at 532 and $355 \mathrm{~nm}$, using 607 and $387 \mathrm{~nm}$ Raman signals. For both systems, the infrared radiation is acquired in analog mode using an APD detector, the 355 and $532 \mathrm{~nm}$ backscattered radiation is acquired both in analog and photon-counting modes, while the Raman backscattered radiation at 387 and $607 \mathrm{~nm}$ is detected in photon-counting mode only for EOLE and both in analog and photon-counting modes for MUSA. MUSA and EOLE laser repetition rates are 20 and $10 \mathrm{~Hz}$ respectively, and the range resolutions were 3.75 and $7.5 \mathrm{~m}$, therefore the comparison was carried out reducing all the lidar signals at the lowest resolution $(7.5 \mathrm{~m})$.

In the comparison, the atmospheric molecular backscatter signals were also used. They were retrieved from the pressure and temperature vertical profiles provided each day by a radiosounding launched by the Hellenic National
Meteorological Service (HNMS) at about 12:00 UTC from a site located $12 \mathrm{~km}$ far away from measurement site and at an altitude of $10 \mathrm{~m}$ a.s.l.

A total of 6 daytime and 7 nighttime measurement sessions were performed during the campaign. Each session had a duration of about 2-3 hours allowing to select a sufficient long time window for the comparison (at least 30 minutes) in which the atmospheric conditions and layering were quite stable.

The range corrected signals were processed using the Single Calculus Chain (SCC) [8, 9], the centralized analysis tool developed within EARLINET in order to process in an automatic way the data measured by the network stations, and a set of software tools, specially developed for the intercomparison campaigns [2].

Whenever a problem was detected, a possible reason was identified, and the corresponding correction was applied in the next measurement session or in the signal processing.

\section{RESULTS}

We present an example of comparison of measurements performed in nighttime conditions on 26 September 2016 from 18:30 to 20:10 UTC. Fig. 1 shows the time evolution of the RCS at 1064 $\mathrm{nm}$ measured by MUSA for the whole measurement session. The red square indicates the time window (18:44 - 19:44 UTC) where the RCS of both systems were averaged for the comparison. The selected time window was characterized by quite stable atmospheric conditions.

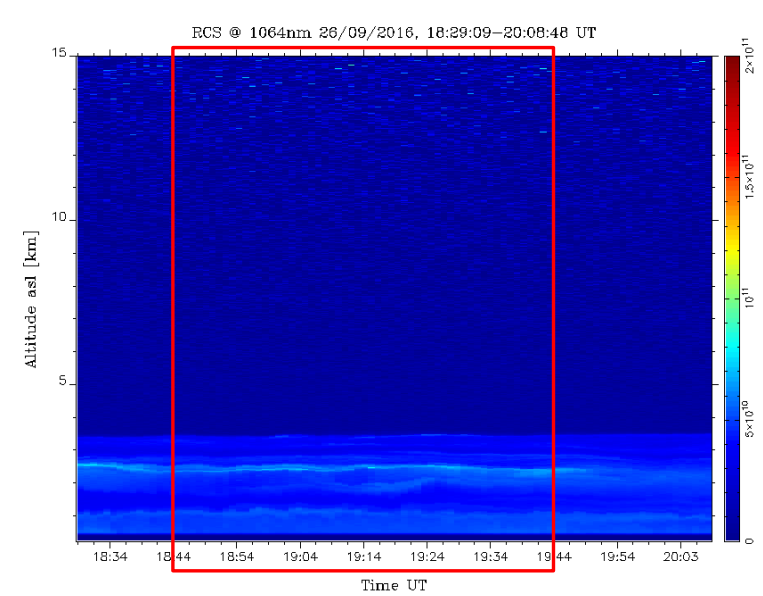

Figure 1 Time evolution of the RCS at $1064 \mathrm{~nm}$, measured on 26 September 2016 by MUSA (18:30 20:10 UTC) in Athens during ATHLI16. 
The comparison allowed us to identify two technical problems on the EOLE infrared channel.

The first one was an incorrect setting of the trigger delay (i.e. the delay between the electronic start of the measurement and the effective time of the laser light emission) which was corrected by minimizing the vertical scale shift between EOLE and MUSA RCS. The second problem on the EOLE infrared channel was the presence of electronic distortions which was fixed by subtracting the dark current signal from the measured lidar signals. We concluded that this correction was particularly significant at $1064 \mathrm{~nm}$.

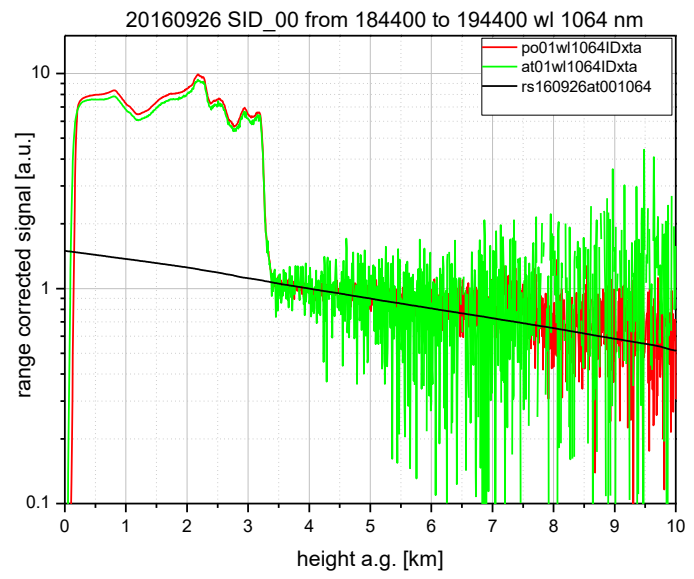

Figure 2. Comparison of RCS at $1064 \mathrm{~nm}$.

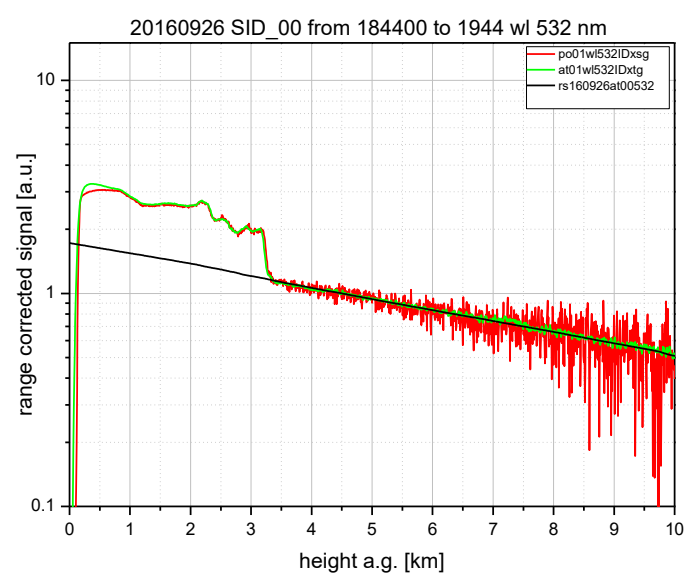

Figure 3. Comparison of RCS at $532 \mathrm{~nm}$.

Figs. 2-6 show the comparison of the RCS at 1064, $532,355,607$ and $387 \mathrm{~nm}$ measured by MUSA (red line) and EOLE (green line) and averaged in the time window shown in Fig. 1. In all the figures it is also reported the molecular backscattering (black line) at the corresponding wavelength. The signals and the molecular backscattering have been normalized in the aerosol free region. A large urban aerosol layer up to about $3.5 \mathrm{~km}$ is present.

From the comparison, it is evident the general good agreement between the elastic signals of EOLE and MUSA systems.

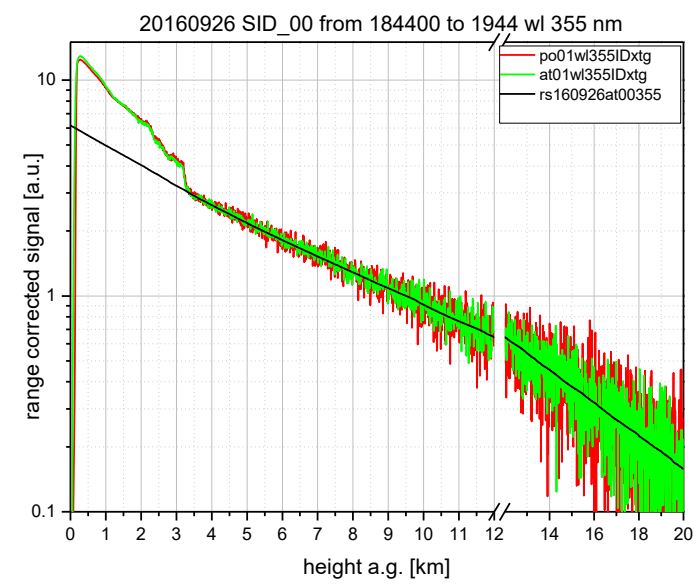

Figure 4. Comparison of RCS at $355 \mathrm{~nm}$.

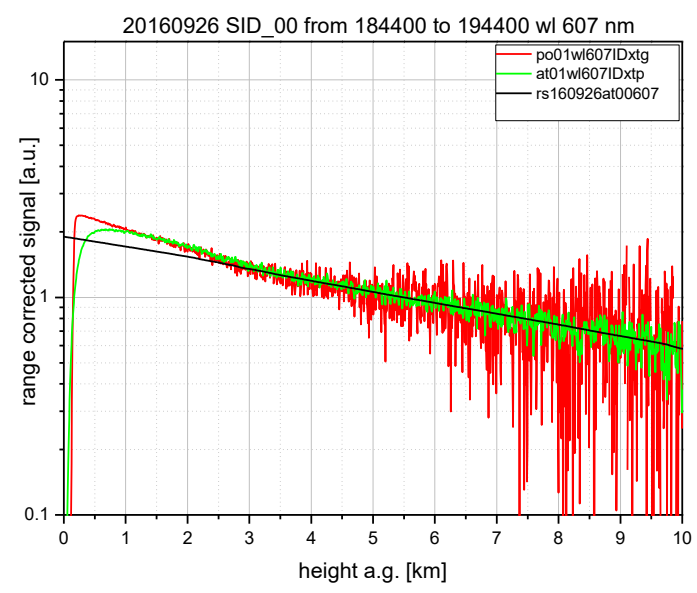

Figure 5. Comparison of RCS at $607 \mathrm{~nm}$.

The relative differences between EOLE and MUSA RCS at $1064 \mathrm{~nm}$ are within 6\% in the range where most of the aerosol is resided (up to about 3 $\mathrm{km})$. Above this range the relative differences are larger $(20 \%$ below $5 \mathrm{~km})$ because the aerosol load is quite low and as a consequence the signals of both lidars are quite noisy. The signals at 532 (355) $\mathrm{nm}$ agree within $2 \%$ (3\%) up to $3.5 \mathrm{~km}$ and within $5 \%(10 \%)$ in the range $3.5-6 \mathrm{~km}$.

The Raman signals show good agreement above $1.2 \mathrm{~km}$ and $1.5 \mathrm{~km}$ at 607 and $387 \mathrm{~nm}$ respectively. The large discrepancy at lower ranges is related to the different acquisition mode used by the two lidars: EOLE Raman signals are acquired using 
photon-counting mode while MUSA ones are detected in both analog and photon-counting mode and the corresponding glued signal is provided. As a consequence the EOLE Raman signals are saturated at low ranges whereas for MUSA system the analog signals start to play an important role.

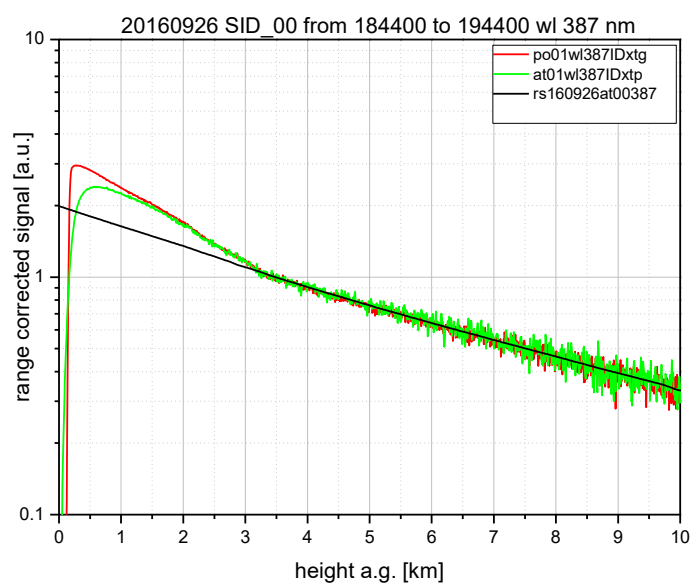

Figure 6. Comparison of RCS at $355 \mathrm{~nm}$.

We also calculated the mean relative deviations, averaged within the large aerosol layer present between 200 and $3500 \mathrm{~m}$ (see Tab 1). The results show a good agreement, but with large standard deviations due to the signal noise.

Table 1. Mean relative difference between EOLE and MUSA RCS, calculated within the aerosol layer between 0.2 and $3.5 \mathrm{~km}$.

\begin{tabular}{|c|c|}
\hline $\boldsymbol{\lambda} \mathbf{( n m})$ & $\mathbf{0 . 2} \mathbf{- 3 . 5} \mathbf{~ k m}$ \\
\hline 1064 & $-0.05(0.02)$ \\
\hline 532 & $0.01(0.03)$ \\
\hline 355 & $-0.0003(0.0276)$ \\
\hline 607 & $-0.02(0.09)$ \\
\hline 387 & $-0.05(0.08)$ \\
\hline
\end{tabular}

\section{CONCLUSIONS}

The lidar intercomparison campaign ATHLI16 was addressed to check the quality of the EOLE system through the comparison with the EARLINET reference lidar system MUSA. The results show a good performance of the EOLE system in terms of RCS comparison according to the EARLINET standards $[2,5]$. The discrepancy at low ranges of Raman signals will be solved by upgrading the Raman optical channels also with analog acquisition. The intercomparison evidenced the importance of subtracting the dark to the $1064 \mathrm{~nm}$ measurement regularly in order to minimize electronic distortions. For the same optical channel, the correct trigger delay value was determined as well. We also tried, as a preliminary stage, to compare the optical products (aerosol backscatter and extinction), retrieved using the SCC, obtaining promising results (examples will be presented at the conference).

\section{ACKNOWLEDGEMENTS}

This project has received funding from the European Union's Horizon 2020 research and innovation programme under grant agreement No 654109.

\section{References}

[1] Pappalardo, G., et al., 2014: EARLINET: towards an advanced sustainable European aerosol lidar network, Atmos. Meas. Tech., 7, 2389-2409, doi:10.5194/amt-7-2389-2014.

[2] Wandinger, U., et al., 2016: EARLINET instrument intercomparison campaigns: overview on strategy and results. Atmos. Meas. Tech., 9, 1001-1023, doi:10.5194/amt-9-1001-2016.

[3] Belegante, L., et al., 2017: The lidar calibration centre: a multi installation facility in the framework of ACTRIS. In: Proc. 28th International Lidar Aerosol Conference (28th $I L R C)$. This volume.

[4] Freudenthaler, V., et al.: Internal quality assurance tools, Atmos. Meas. Tech. Discuss., in prep.

[5] Matthias, V., et al., 2004: Aerosol lidar intercomparison in the framework of the EARLINET project. 1. Instruments, Appl. Opt., 43, 961-976, doi:10.1364/AO.43.000961.

[6] Kokkalis, P., et al., 2012: The EOLE lidar system of the National Technical University of Athens. In: Proc. 26th International Laser Radar Conference (26 $6^{\text {th }}$ ILRC), pp. 629-632.

[7] Madonna, F., et al., 2011: CIAO: the CNRIMAA advanced observatory for atmospheric research, Atmos. Meas. Tech., 4, 1191-1208, doi:10.5194/amt-4-1191-2011.

[8] D'Amico, G., et al., 2016: EARLINET Single Calculus Chain - technical - Part 1: Preprocessing of raw lidar data, Atmos. Meas. Tech., 9, 491-507, doi:10.5194/amt-9-491-2016.

[9] Mattis, I., et al., 2016: EARLINET Single Calculus Chain - technical Part 2: Calculation of optical products, Atmos. Meas. Tech., 9, 30093029, doi:10.5194/amt-9-3009-2016. 